The $B D J$ News section accepts items that include general news, latest research and diary events that interest our readers.

Press releases or articles may be edited, and should include a colour photograph if possible. Please direct your correspondence to the News Editor, Arveen Bajaj at the BDJ, The Macmillan Building, 4 Crinan Street, London N1 9XW or by email to bdj@bda.org

\section{Oral disease prevention}

Francesco D'Aiuto of the UCL Eastman Dental Institute has been awarded an IADR/Colgate Research in Prevention Travel Award. Established by the International Association for Dental Research (IADR) and supported by the Colgate-Palmolive Company, it enables young investigators presenting original research in the area of oral disease prevention to travel to the International Association for Dental Research General Session. Each recipient receives US\$2,000 and a plaque.

\section{Charges change}

From 1 April, NHS dental charges in England will increase in line with inflation (approximately $2.7 \%$ ) as follows: band $1 £ 15.90$, band $2 £ 43.60$, band 3, £194.

Stainless steel crowns for minors are to move from band 3 to band 2 . There have been no changes to patient charges in Wales.

\section{Long service to dental profession recognised}

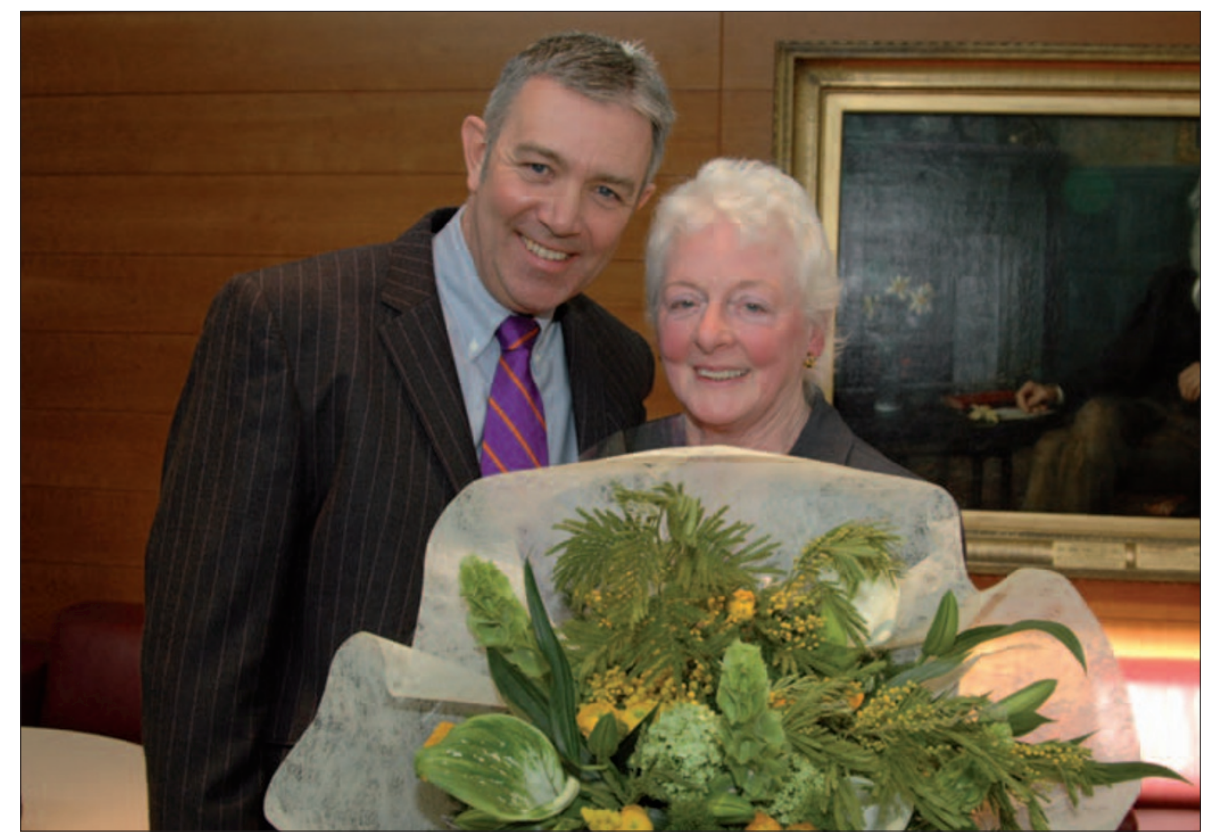

Mary Newing, Editor of Dental Practice, is presented with a bouquet by Stephen Hancocks, $B D J$ Editor-in-Chief, on behalf of all her friends in the dental profession, to mark her retirement after nearly 40 years. The presentation took place at the British Dental Association. Last month Mary was also given an honorary Fellowship in Dental Surgery from the Eastman Dental Institute in recognition of her support in championing its work. She was awarded an MBE in 1997.

\section{New CDO for Scotland}

Margie Taylor has been appointed as Scotland's new Chief Dental Officer. Miss Taylor (51) has extensive experience in dentistry and is currently Consultant in Dental Public Health at NHS Lanarkshire. Before joining NHS Lanarkshire in 1994, she worked in Fife and Lothian as Chief Administrative Dental Officer and in clinical dentistry, respectively.

Born in Edinburgh and educated at James Gillespie's High School, Miss
Taylor graduated from Edinburgh University in 1978. She gained an MSc in Community Medicine in 1985 and an MBA in 1996. She is a fellow in dental surgery of the Royal College of Surgeons of Edinburgh and the Royal College of Physicians and Surgeons of Glasgow and an honorary member of the Faculty of Public Health Medicine. Miss Taylor has also held posts as Honorary Senior Lecturer at St Andrews, Glasgow and Dundee universities.

She will take over on May 1 from current CDO Ray Watkins, who is leaving to take up a post as Consultant in
Dental Public Health at NHS Grampian. Mr Watkins will continue to act as Chief Dental Officer until Miss Taylor takes up her post.

British Dental Association (BDA) Director for Scotland Andrew Lamb welcomed the appointment and said, 'Given that two years after the launch of the Scottish Executive's Action Plan, fewer patients are registered with an NHS dentist than were before and fewer dentists who provide NHS treatment are regarded as being committed according to Executive criteria, Miss Taylor faces significant challenges in her new role.' 


\section{Tooth brushing link to epilepsy seizures}

Tooth brushing may trigger seizures in certain people with epilepsy according to an article published in the last month's issue of Neurology, the journal of the American Academy of Neurology.

Researchers say lesions in a specific part of the brain may be a cause in some people and the article reviewed the cases of three adults with epilepsy who experienced seizures while brushing their teeth. Two of the adults reported some of their seizures occurred when they brushed certain areas of their mouth. The seizures varied from jerking and twitching of the face to salivating vigorously. One patient was unable to let go of the toothbrush during the seizure. The seizures were confirmed by video monitoring.

Using MRI scans, researchers found all three patients had lesions in the somatosensory area of the brain, which is close to the hand and speech motor areas. 'The rhythmic act of brushing teeth may excite an already overly excitable area of the brain and is similar to photosensitive epilepsy, which involves seizures triggered by flashing lights and moving patterns,' said study author Wendyl D'Souza, who is with the Department of Neurology and Neurological Research at St Vincent's Hospital, the University of Melbourne, Australia.

He added that since tooth brushing involved persistent rhythmic action, this may explain why this trigger is more likely to induce seizures in the somatosensory area of the brain compared to other oral stimuli, such as eating.

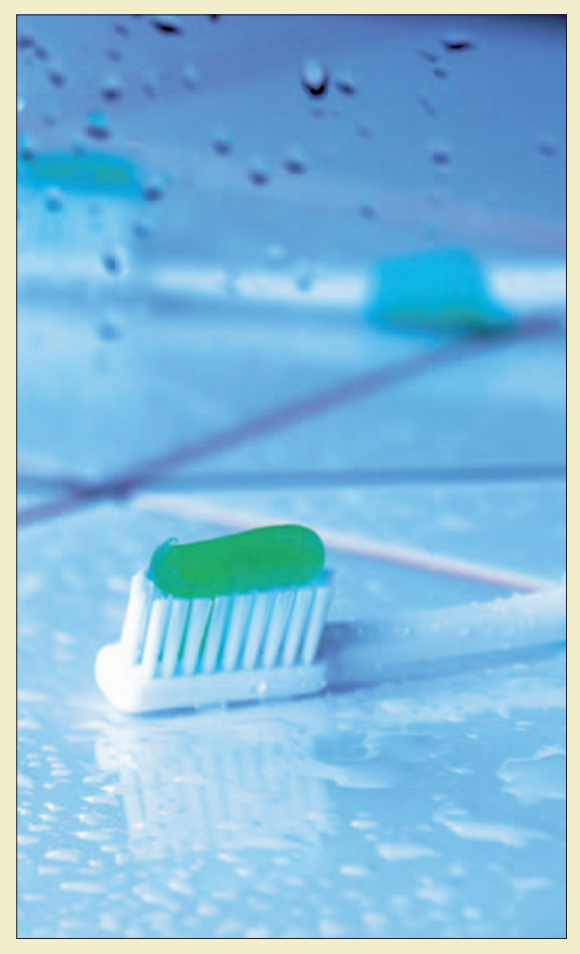

\section{First European president installed}

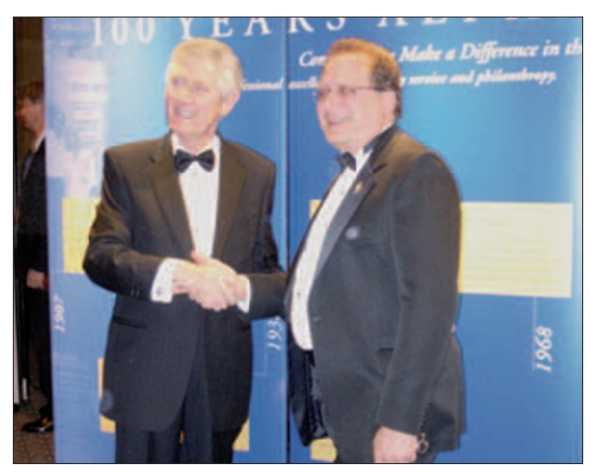

Alpha Omega (A0), the international dental fraternity, has welcomed its first UK-based President in 100 years. In assuming the role of International President, John Wolffe BDS, from Hendon in London, will be spearheading the organisation's educational and charitable roles as it seeks to provide dental health to deprived communities worldwide.

Having been installed at the fraternity's annual convention in Las Vegas, he assumes the role, having served as an international officer for the past two years.

John succeeds Steven Braunstein DDS of Buffalo, New York, who served as the 2006 International President. His election to the post represents only the second time a non-North American has led the fraternity - the last being 17 years ago, following the appointment of Yehuda Kaufman of Tel Aviv. 


\section{Patient focussed study wins prize}

Dr Janice Ellis and a team from Newcastle recently won the Schottlander Poster Prize at the British Society for the Study of Prosthetic Dentistry (BSSPD) Conference in Newcastle.

The prize-winning poster, entitled Understanding the edentulous plight; the patients' stories, focussed on gaining a better understanding of the problems associated with the edentulous condition.

The study reported on the differences recorded between patients wearing conventional dentures and those wearing implant-supported overdentures. It also distinguished between the different patient profiles depending upon whether the patient was a late acquirer, an early acquirer or a compounded patient.

Dr Ellis received her prize from Dr Brian Schottlander at the BSSPD conference dinner held at the Baltic Exchange on Tyneside. The Schottlander Paper Prize winner was Dr David Newsum from

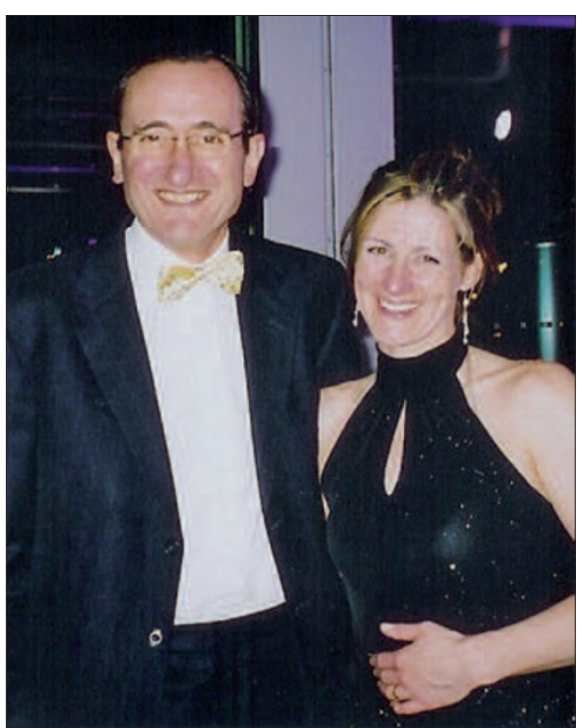

King's College, London. He will be presented with his prize at a dinner later on in the year.

\section{Professional indemnity information online}

The General Dental Council has produced an information sheet on indemnity to answer the questions dental professionals most frequently ask. The information sheet, which is available on the GDC website, aims to provide greater clarity and certainty to registered dental professionals on this complex issue and answers questions covering risk cover, employer arrangements and what points to check when choosing a policy. www.gdc-uk.org

\section{Supporting undergraduate research}

This year's 30th BDA/Dentsply Student Clinician Award went to Elizabeth Paice, a final year dental student at Bristol Dental School. She was presented with her award at anniversary dinner held at the Savoy Hotel in London recently.

The BDA/Dentsply Student Clinician Awards programme supports international undergraduate study and focuses on original research, highlighting the continuous bond that exists between the profession and the dental industry.

Over the past year, Elizabeth Paice has undertaken a research project in the Clinical Trials Unit under the supervision of Susan Hooper, Consultant/Senior Lecturer in the Division of Restorative Dentistry. Her winning presentation, The Erosive Effects of Saliva on Enamel and Dentine following Chewing Gum: an Ex-Vivo study, won her an all expenses paid trip to the American Dental Association's Annual Conference in San Francisco in September. She commented, 'The opportunity to be so fully involved with research during my undergraduate studies has been a real eye-opener to wider career opportunities and emphasised the relevance of research to dental practice.'

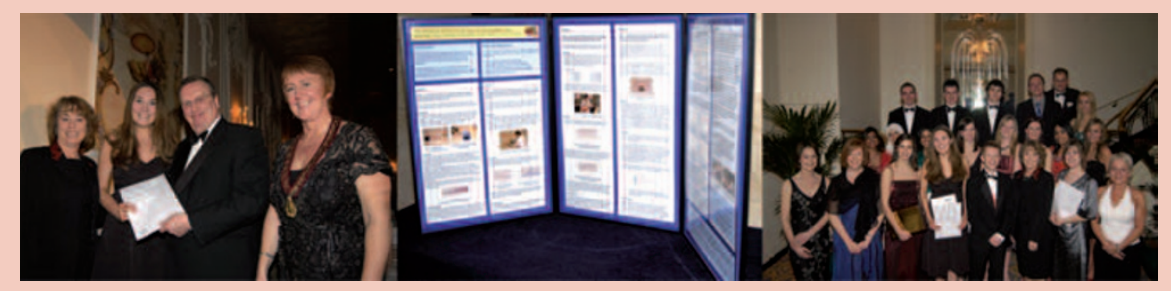




\section{Computer aided self-help for anxious patients}

April

Irish Dental Association Annual Scientific Conference

Date: 18-21 April 2007

Venue: Rochestown Park Hotel, Cork, Ireland www.dentist.ie

The Society of Manchester Dental Alumni (SOMANDA) biennial meeting and reunion Date: 20 April 2007

Venue: University of Manchester

Email: carolynstylianou@ntlworld.com

The International Team for Implantology

(ITI) World Symposium 2007

Date: 26-28 April 2007

Venue: New York City

www.iti.org

29th Asia Pacific Dental Congress

Date: 26-28 April 2007

Venue: Jakarta, Indonesia

Tel: +62 217260088

Fax: +62 217397555

www.apdc2007jakarta.com

May

ADI 20th Anniversary Congress

Date: 3-5 May 2007

Venue: ICC in Birmingham

www.adi.org.uk

International Osteology Symposium 2007 Date: 10-12 May 2007

Venue: Grimaldi Forum, Monaco

www.osteology-monaco.org

DSTG Annual Symposium 2007

Date: 15 May 2007

Venue: Birmingham Dental Hospital www.dstg.co.uk

BDA British Dental Conference and

Exhibition 2007

Date: 24-26 May 2007

Venue: Harrogate International

Centre (HIC)

Tel: 02075634590

Email: events@bda.org
Anxious patients in need of dental care could soon have their fears allayed by a computer-aided programme. A multinational research team at King's College London Dental Institute has announced that it has successfully completed the first development stage of its Computer Assisted Relaxation Learning UK (CARL-UK).

The system offers self-help for dental fear to thousands of people who avoid the dentist or seek dental treatment under sedation or general anaesthesia, costing the General Dental Service of the NHS millions of pounds each year.

CARL-UK, when completed in the next year, is expected to link to FearFighter, an established computer-aided self-help system that the National Institute for Clinical Excellence (NICE) recommends for panic, phobias and anxiety. FearFighter on the internet is being used increasingly and effectively by Primary Care Trusts around the country.

CARL-UK is being developed by a team of dentists and experts in Cognitive Behaviour Therapy (CBT) headed by Professor Peter Milgrom, Visiting Professor of Pain and Anxiety Control at King's College London Dental Institute and Emeritus Professor Isaac Marks of King's College London Institute of Psychiatry. Professors Milgrom and Marks have between them over 60 years of clinical experience treating fearful patients and are internationally recognised.

Professor Milgrom said, 'In trials in

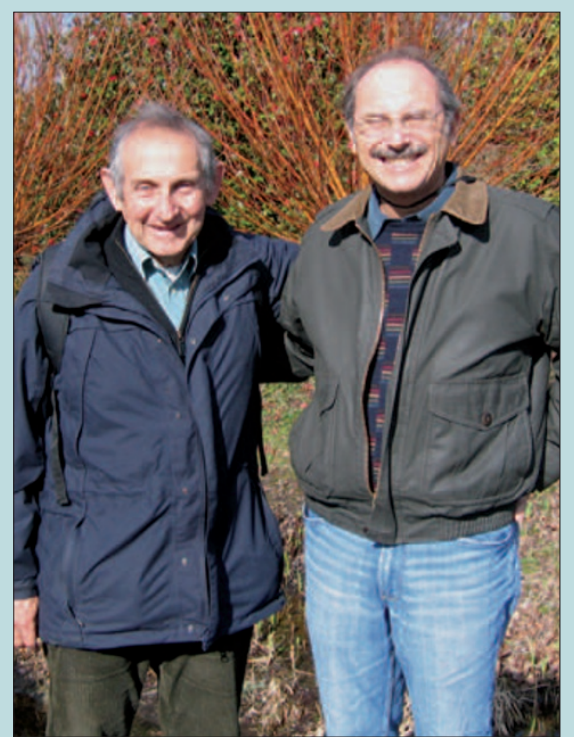

Pictured above, Professors Milgrom and Marks

America, CARL-UK greatly lowered barriers to anxious patients seeking dental care. CBT helped people reduce dental fears very successfully at relatively low cost.'

The King's research team includes Dr Carole Boyle, a dentist and Associate Specialist in the Department of Sedation and Special Care Dentistry and Professor Tim Newton, a psychologist in the Department of Oral Health Services Research and Dental Public Health.

Phase I of the program development has been supported, in part, by the Society for Anaesthesia in Dentistry (SAAD). The Dental Institute already does online training for general dental practitioners in dental specialties. 